\title{
Psychophysical adaptation of visually impaired students through Showdown game
}

\author{
Sergey Kokhan ${ }^{1 *}$, Yana Grabovskaya ${ }^{1}$, Nina Vinogradova $^{1}$, Luiza Nadeina $^{2}$ \\ ${ }^{1}$ Trans-Baikal State University, 672039, Chita, Russia \\ ${ }^{2}$ National Research Tomsk Polytechnic University, 634050, Tomsk, Russia
}

\begin{abstract}
The article deals with the problem of visual defects compensation for psychophysiological activity and adaptation of students in the process of studying at a university. The aim of the study was to test the effect of showdown training on several indicators of growth in physical activity and capabilities, including psychological adaptation. The data obtained from showdown classes in combination with APE showed a significant decrease in the general experience of students with visual impairment, the quality of interpersonal communication and communication capabilities increased. There was also a significant increase in the range of motion in the joints, an improvement in fine motor skills of the hands, and the rate of hand movements. The results of the experiment show that showdown is a promising effective option for classes and trainings that contribute to the improvement of physical activity, psychological adaptation and a positive effect on physical activity and endurance of students with abnormal vision of students at the university.
\end{abstract}

\section{Introduction}

The provided opportunity to obtain higher education for students with sensory, physical disorders, diseases and developmental anomalies is currently carried out in accordance with the regulated documents of the state educational policy [1,2]. Students with disabilities need to provide special conditions for successful adaptation and study at the university. A set of measures aimed at meeting the special needs of these students includes: providing an accessible architectural environment, support in the educational space, psychological and pedagogical support, socio-cultural and physical adaptation and rehabilitation.

Adaptation problems when students with disabilities enroll in a university are associated with a sense of isolation, loneliness, feelings of separation and separation from home, increased interpersonal conflicts [3].

The adaptation of students with vision problems at the university is heterogeneous and complicated by numerous negative factors: lack of communication skills, phobias, poor orientation in society, the habit of condescending attitude, lack of confidence in their abilities and capabilities. In visually impaired persons, there are changes in the functional state of the motor analyzer. It causes decrease in orientation in space, general coordination of movements, accuracy and speed, formation of motor skills [4,5].

A variety of psychophysical characteristics and disorders of vision development significantly complicates the control of the students' physical fitness level. Various psychophysical characteristics of students with disabilities reveal special educational needs that require specific adaptation of both the organizational and structural and the content side of the pedagogical process [6].

One of the most psychological reactions of impaired vision, due to the student's perceived limitations in orientation in space and interpersonal communication is helplessness. It leads to the formation of a stable feeling of subjective loneliness, expressed in the alienation of the professional training subjects, the realization educational of the university program mastering impossibility, occupying a more or less stable position in the peer group, and finding understanding and recognition of his/her own personality by others. The subjective experience of loneliness by students with impaired vision makes it difficult for them to successfully enter the wide context of social relations, and the lack of a sense of community leads to the underdevelopment of constructive relations with the world [7,8].

In the process of general psychological preparation, attention is paid to competitive motivation, emotional stability, self-regulation and discipline in a competitive situation [9].

The experience of domestic and foreign authors working with different age categories of disabled people with visual impairments shows that one of the main methods of correcting psychophysical development is adapted

\footnotetext{
* Corresponding author: ispsmed@mail.ru
} 
physical education (APE) and Paralympic sports [10]. The sport of the blind is represented by a small category of collective and individual sports and games. These sports and games include goalball and showdown [11].

For young people with visual impairments, especially for the totally blind, showdown classes are one of the ways to improve their spatial orientation, the possibility of expanding communication ties, prevention of hypodynamia, correction and compensation of the physical and motor spheres, the functional state of the cardiovascular and respiratory systems of the body. It should be noted that informing and accompanying students with abnormal vision, in the process of showdown classes, contribute to their adaptive and psychological stress resistance [12].

Teaching students with visual impairment to motor game actions, using play adaptive and corrective exercises that form play skills, technique, motor skills, depend on the degree of visual defect and the presence of secondary deviations (flat feet, scoliosis). The role of the vestibular apparatus for maintaining equilibrium and spatial orientation significantly increases due to the lack of visual control over the position of the body in space, and it leads to a significant increase of its sensitivity [13].

It is known that during the period of schooling, blind and visually impaired children have a significant lag behind the norm in physical and mental development. Physical education teachers, without special retraining, do not know the methods and forms of adapted, dosed, individual physical loads. As a result, the existing deviations in schoolchildren, which are persistent, cannot be fully or partially compensated and coordinated during school education [14].

Consequently, young people with abnormal vision, entering the university, are mostly physically undeveloped, not prepared for APE classes, and have insufficient understanding of the sport of the blind.

Showdown classes refer to sports game activity that contributes to the psychophysical adaptation of the blind and visually impaired, the creation of certain compensatory-corrective conditions, the acquisition of special experience and skills that are successfully used not only in everyday life, but also in the competitive period.

In the literature available to us, there is no information about conducting investigations to study the influence of the showdown game as a means of correction, physical and mental development of young people with various degrees of impairment during their study at the university.

Thus, the lack of complete information on the popularization of showdown in higher educational institutions and the lack of development of ways to solve this problem, which is extremely relevant for improving the physical development of blind and visually impaired students, gives full reason to consider our study of the influence of play as an adaptive means of physical and mental development, extremely relevant.

The aim of the study is substantiation of the application of an integrated approach of psychophysical correction and adaptation of blind and visually impaired students involved in showdown.

Achieving the aim is possible by solving the following tasks:

1. Studying the state of the problem of increasing the motor and physical activity of blind and visually impaired students.

2. Experimentally check the effectiveness of the application of the methodology of complex APE classes and playing skills in showdown.

\section{Materials and Methods}

A set of methods was used, including: analysis of the available general and specialized literature on research problems, a pedagogical experiment with giving a talk, interviews, remedial and practical exercises, and statistical processing.

10 male students with visual impairments who entered the 2017-2018 academic years voluntarily took part in the research. Of these, 5 people from Trans-Baikal State University and 5 students from Chita Medical College, who expressed a desire to learn how to play and perform at showdown competitions. Four people of them have the first group of visual disabilities (Group I), three people have the second group of visual disabilities (Group II), and three people have the third group of visual disabilities (Group III).

The median age was $23,1 \pm 4,2$. Six students live with their parents, and four students live in the student dormitory.

The measurement of students' physical development level with visual impairments was conducted in October and the control one was in June. The training process took place 3 times a week for 2 hours for 9 months during the educational process at the university. Physical activity during the training process included APE classes. The effectiveness of the training was determined by the results of the performance in the personal championship at the regional and city competitions on showdown.

A psychodiagnostic survey of students with visual impairment in introductory and control classes was conducted using the "Differential questionnaire of the loneliness DQEL-3" method experience [15].

The training process took place on the site of the medical and social rehabilitation center for disabled people "Rostok" of the Trans-Baikal region and consisted in improving the level of physical endurance, coordination of movements, speed-strength qualities, improving hearing and orientation in space and improving fine motor skills of the hands.

The results were processed using mathematical statistics, using SPSS 20, Microsoft Excel program. It allows to assess the level of psychophysical activity during showdown training. 


\section{Results and Discussion}

Before the training process students with visual impairments were interviewed to determine their physical mobility and exercise. During the conversation it was established that out of 10 participants, only 3 people have little experience in physical and recreational detail. All expressed the desire to engage in showdown and APE to promote health and develop physical endurance. During the experimental physical and recreational classes and showdown trainings, height-weight measurements and lung capacity (LC) were carried out. The benchmark growth figures were virtually unchanged at an average of $163,2 \pm 11,2$. Reliable changes in body weight were recorded at the beginning of the experiment - 70,1 $\pm 2,2$, after the experiment - 62,2 $\pm 0,8(\mathrm{P}-0,001)$. LC increased without reliable shifts, 1910,3 $\pm 4,7$ - at the beginning and 2010,2 $\pm 5,57(\mathrm{P}-0,001)$.

As a result of psycho-diagnostic examination of students with disabilities in the introductory class using the method "Differential questionnaire of the loneliness DQEL-3" (E. N. Osin, D.A. Leontiev) experience data were obtained on the severity of indicators on scales: "Dependence on communication," "Positive loneliness" and "The general experience of loneliness."

Analysis of obtained data showed that 6 respondents have high level according to the scale "dependence on communication", and it indicates negative idea about the solitude and tendency to search for contact with any price for the purpose to avoid the situations of solitude.

As for the scale "Positive loneliness", only 1 person has high indicators. He is able to experience positive emotions in situations of solitude. And he knows how to appreciate them and tends to consciously spend time with himself in his own life. Other students demonstrate an inability to find a resource in situations of solitude and a lack of positive emotions due to privacy.

On the general experience of loneliness scale, the majority of students with disabilities (7 people) have high values. They experience a painful experience of loneliness associated with the lack of close social contacts and communication. They consider themselves lonely. This highlights the serious problems in interpersonal communication and the need to form a stable "I-position" [16].

The control survey of blind and visually impaired students at the final stage of the class showed the following results: on the scale "Dependence on communication": 8 students had high rates; on the scale "Positive loneliness" 3 students had high rates; on the scale "General experience of loneliness" 3 students had high rates.

Based on the data obtained, we can say that showdown classes have almost halved the number of students with high rates of general experience of loneliness. The quality of interpersonal communication has increased due to the developed skills to control their emotions, to influence the emotional state of other people, to assess their own efforts in the team game.

As the result of the pedagogical experiment on the organization of the showdown training process, the improvement of indicators reflecting the functional indicators of the body is registered. The control results of blood pressure, heart rate and functional samples indicate a significant improvement in the response of the cardiovascular and respiratory systems of blind and visually impaired students engaged in showdown (Table I).

Table 1. Dynamics of the subjects functional state before and after the pedagogical experiment

\begin{tabular}{|c|c|c|c|}
\hline Testing figures & $\begin{array}{l}\text { Before } \\
\text { experiment } \\
X \pm m\end{array}$ & $\begin{array}{l}\text { After } \\
\text { experiment } \\
X \pm m\end{array}$ & $\mathrm{P}$ \\
\hline $\begin{array}{l}\mathrm{AD}(\mathrm{mm} \quad \mathrm{Hg}) \text { : } \\
\text { systolic } \\
\text { diastolic }\end{array}$ & $\begin{array}{c}127 \pm 1,9 \\
80,2 \pm 2,2\end{array}$ & $\begin{array}{c}114,2 \pm 1,8 \\
72,2 \pm 2,1\end{array}$ & $\begin{array}{c}0,001 \\
0,01\end{array}$ \\
\hline $\begin{array}{l}\text { Heart rate }(\mathrm{bpm}) \text { : } \\
\text { before classes } \\
\text { after classes }\end{array}$ & $\begin{array}{l}71,6 \pm 1,7 \\
93,7 \pm 2,5\end{array}$ & $\begin{array}{l}62,0 \pm 1,3 \\
85,1 \pm 2,4\end{array}$ & $\begin{array}{l}0,01 \\
0,01\end{array}$ \\
\hline $\begin{array}{l}\text { Breath-holding: } \\
\text { on inspiration } \\
\text { (Stange test) (s) } \\
\text { on exhalation } \\
\text { (Gench test) (s) }\end{array}$ & $\begin{array}{l}20,9 \pm 1,4 \\
15,8 \pm 1,0\end{array}$ & $\begin{array}{l}29,2 \pm 0,6 \\
24,0 \pm 1,1\end{array}$ & $\begin{array}{l}0,001 \\
0,001\end{array}$ \\
\hline $\begin{array}{l}\text { Martine's test }(20 \\
\text { squats): } \\
\text { heart rate before } \\
\text { exercise (s) } \\
\text { heart rate after } \\
\text { exercise (s) }\end{array}$ & $\begin{array}{c}69,9 \pm 0,9 \\
117,3 \pm 2,8\end{array}$ & $\begin{array}{c}63,0 \pm 1,4 \\
100,6 \pm 2,5\end{array}$ & $\begin{array}{l}0,01 \\
0,01\end{array}$ \\
\hline
\end{tabular}




\begin{tabular}{llll}
$\begin{array}{l}\text { Rufier's test } \\
\text { (points) }\end{array}$ & $12,1 \pm 0,8$ & $5,9 \pm 0,7$ & 0,05 \\
& & & \\
Orthostatic test (c): & $69,1 \pm 1,7$ & $64,1 \pm 1,6$ & 0,05 \\
& $98,5 \pm 1,8$ & $90,5 \pm 3,1$ & 0,01 \\
& & & \\
$\begin{array}{l}\text { Lying heart rate } \\
\text { Standing down }\end{array}$ & & \\
\hline
\end{tabular}

The experimental results of control studies indicate an increase in the amplitude of movements in the joints of the upper extremities, fine motor skills of the hands. It significantly increases the rate of wrist movements, in the process of attacking and defensive strikes in game actions (Table II).

Table 2. Indicators of the motion range in the joints upper and lower extremities in disabled people (in degrees)

\begin{tabular}{|c|c|c|c|c|c|}
\hline Joint name & & $\begin{array}{l}\text { Before } \\
\text { experi } \\
\text { ment } \\
X \pm m\end{array}$ & $\begin{array}{l}\text { After } \\
\text { experi } \\
\text { ment } \\
X \pm m\end{array}$ & $\mathrm{P}$ & $\begin{array}{l}\text { Rate } \\
\text { indi } \\
\text { cator }\end{array}$ \\
\hline $\begin{array}{l}\text { Shoulder } \\
\text { (flexion } \\
\text { extension) }\end{array}$ & $\begin{array}{l}\text { left } \\
\text { right }\end{array}$ & $\begin{array}{c}124,7 \\
\pm 1,7 \\
126 \pm \\
4,2\end{array}$ & $\begin{array}{c}137 \pm 2 \\
1 \\
129,1 \pm \\
1,1\end{array}$ & $\begin{array}{l}0, \\
01 \\
0, \\
01\end{array}$ & $\begin{array}{c}130- \\
150\end{array}$ \\
\hline $\begin{array}{l}\text { Elbow } \\
\text { (flexure - } \\
\text { straightening) }\end{array}$ & $\begin{array}{l}\text { left } \\
\text { right }\end{array}$ & $\begin{array}{c}73,5 \pm \\
2,7 \\
122,7 \\
\pm 2,8\end{array}$ & $\begin{array}{c}87,3 \pm 1, \\
2 \\
136,4 \pm \\
2,8\end{array}$ & $\begin{array}{l}0, \\
01 \\
0, \\
01\end{array}$ & $\begin{array}{c}140- \\
150\end{array}$ \\
\hline $\begin{array}{l}\text { Wrist (flexion } \\
\text { - extension) }\end{array}$ & $\begin{array}{l}\text { left } \\
\text { right }\end{array}$ & $\begin{array}{l}108,4 \\
\pm 4,1 \\
112,3 \\
\pm 3,9\end{array}$ & $\begin{array}{c}113 \pm 3 \\
3 \\
123 \pm 2 \\
9\end{array}$ & $\begin{array}{l}0, \\
01 \\
0, \\
01\end{array}$ & $\begin{array}{l}150- \\
160\end{array}$ \\
\hline $\begin{array}{l}\text { Wrist } \\
\text { (lead- } \\
\text { adduction) }\end{array}$ & $\begin{array}{l}\text { left } \\
\text { right }\end{array}$ & $\begin{array}{c}114 \pm \\
7,5 \\
118 \pm \\
5,1\end{array}$ & $\begin{array}{c}127 \pm 3 \\
2 \\
129 \pm 4, \\
1\end{array}$ & $\begin{array}{l}0, \\
01 \\
0, \\
01\end{array}$ & $\begin{array}{c}150- \\
160\end{array}$ \\
\hline
\end{tabular}

Thus, the use of dosed, adaptive physical loads, the assimilation of technical and tactical skills, an increase in communicative activity and psychological stability, game practice made it possible to increase the functional and motor capabilities of students with visual impairment. They contributed to an increase in their adaptive capabilities, socialization and integration into society.

\section{Conclusion}

The research data, the obtained results of the registered changes in the readiness of the blind and visually impaired students during the showdown training sessions showed significant changes in their psychophysical training and capabilities.

Showdown classes contributed to the development of students with visual impairments motor activity, an increase in their communication and adaptive abilities, improvement of physical qualities in order to increase their social activity.

We have proven that visually impaired students find it difficult to cope with the psychological feeling of loneliness. They are in the risk group and are in dire need of psychological and pedagogical assistance during the rehabilitation process to overcome the loneliness they are experiencing. The solution to this problem contributes to their inclusion in the composition of teams in outdoor games.

Students with visual impairments, playing the adapted tabletop sports game showdown, note an increase in physical development, improvement of their sports skills.

The motivational and psychological attitude and full-fledged social adaptation are the key to the success of people with visual analyzer pathology. Adapted tabletop sports games contribute to the adaptation of disabled people to changing living conditions and corrective-compensatory activity of the motor sphere and mobilize moral and volitional qualities.

The principle of the training process realization is revealed not only from the position of motor rehabilitation, as a result of the blind and visually impaired students' goalball lessons. Trainings and performances at sports 
tournaments will contribute to the improvement and restoration of psychophysiological functions. We note the influence of collective play on the intellectual, socio-psychological readiness of the blind, contributing to their strong-willed readiness to overcome difficulties and self-improvement.

Therefore, the effectiveness of the game, as means of correcting the physical and moral development of blind and visually impaired students, is shown on the basis of systematic showdown classes research.

\section{Acknowledgment}

The article was prepared as a part of a scientific grant of the Council for Scientific and Innovative Activities of Trans-Baikal State University No. 294 ГР (2020) "Study of adaptation characteristics of students with disabilities".

\section{References}

1. L.A. Bordonskaya, E.A. Igumnova, K.G. Erdyneeva, G.N. Sleptsova, S.S. Serebryakova, Lecture Notes in Networks and Systems, 131, 871-882 (2020). URL: https://doi.org/10.1007/978-3-030-47415-7 94

2. D.T. Dugarova, S.E. Starostina, S.Z. Kimova, N.A. Kazachek, Indian Journal of Science and Technology, 9(27) (2016). URL: https://www.scopus.com/inward/record.uri?eid=2-s2.084983627650\&doi $=10.17485 \% 2$ fijst $\% 2$ f2016\%2fv9i27\%2f97694\&partnerID https://doi.org/10.17485/ijst/2016/v9i27/97694

3. N.I. Vinogradova, T.A. Khodyukova, S.T. Kokhan, Scientific notes of Trans-Baikal state university, 14(2), 6268 (2019). URL: https://doi.org/10.21209/2658-7114-2019-14-2-62-68

4. L. Zittel, J. Pyfer, D. Auxter, Principles and Methods of Adapted Physical Education \& Recreation (Jones \& Bartlett Publishers, 2016)

5. O.S. Smirnov, A.V. Kornev, Adapted physical education, 4(56), 33- 34 (2013)

6. A.S. Kuznetsov, Z.M. Kuznetsova, Russian Journal of Physical Education and Sport, 14(4), 5-7 (2019)

7. P.G. Gasanova, Psychology of loneliness (Limited Liability Company "Financial Rada of Ukraine", Kiev, 2017)

8. S.T. Kokhan, N.I. Vinogradova, Ya.I. Grabovskaya, Russian Journal of Education and Psychology, 11(1), 7-15 (2020). URL: https://doi.org/0.12731/2658-4034-2020-1-7-15

9. P. Jefferies, Prosthet Orthot Int, 36(3), 278-89 (2012)

10. N. Webborn, Lancet, 7 - 380(9836), 65-71 (2012)

11. A. Fines, M. Block, Sport Education and Society, 2020. URL: https://doi.org/10.1080/13573322.2020.1729113

12. S.T. Kohan, V.O. Simonova, Symbol of Science, 1, 74-75 (2019)

13. M. Marini M., J Sports Med Phys Fitness, 51(2), 227-232 (2012)

14. S. Forrester, Recreational Sports Journal, 39(1), 2-15 (2015). UTL: https://doi.org/10.1123/rsj.2015-0005

15. E.N. Osin, D.A. Leontiev, Differential questionnaire of the experience of loneliness, 2016.

16. I.M. Slobodchikov, Psychological newspaper, 7, 204-207 (2014) 